\title{
Method for short-term prediction of milk yield at the quarter level to improve udder health monitoring
}

\author{
Ines Adriaens, ${ }^{* 1}$ Tjebbe Huybrechts, ${ }^{*}$ Ben Aernouts, ${ }^{*} \dagger$ Katleen Geerinckx, $\ddagger$ Sofie Piepers,$\S$ \\ Bart De Ketelaere, ${ }^{*}$ and Wouter Saeys* \\ *Department of Biosystems, MeBioS, KU Leuven, Kasteelpark Arenberg 30, Box 2456, 3001 Heverlee, Belgium \\ †Department of Microbial and Molecular Systems, Cluster for Bioengineering Technology, KU Leuven, Campus Geel, 2440 Geel, Belgium \\ ‡Province of Antwerp, Hooibeekhoeve, Hooibeeksedijk 1, 2440 Geel, Belgium \\ §Department of Reproduction, Obstetrics and Herd Health, M-Team and Mastitis and Milk Quality Research Unit, Ghent University, \\ Salisburylaan 133, 9820 Merelbeke, Belgium
}

\section{ABSTRACT}

Udder health problems are often associated with milk losses. These losses are different between quarters, as infected quarters are affected both by systemic and pathogen-specific local effects, whereas noninfected quarters are only subject to systemic effects. To gain insight in these losses and the milk yield dynamics during disease, it is essential to have a reliable reference for quarter-level milk yield in an unperturbed state, mimicking its potential yield. We developed a novel methodology to predict this quarter milk yield per milking session, using an historical data set of 504 lactations collected on a test farm by an automated milking system from DeLaval (Tumba, Sweden). Using a linear mixed model framework in which covariates associated with the linearized Wood model and the milking interval are included, we were able to describe quarter-level yield per milking session with a proportional error below $10 \%$. Applying this model enables us to predict the milk yield of individual quarters 1 to $50 \mathrm{~d}$ ahead with a mean prediction error ranging between 8 and 20\%, depending on the amount of historical data available to estimate the random effect covariates for the predicted lactation. The developed methodology was illustrated using 2 examples for which quarter-level milk losses are calculated during clinical mastitis. These showed that the quarter-level mixed model allows us to gain insight in quarter lactation dynamics and enables to calculate milk losses in different situations.

Key words: dairy cow, milk loss, udder health, linear mixed model

Received March 5, 2018

Accepted July 11, 2018.

${ }^{1}$ Corresponding author: ines.adriaens@kuleuven.be

\section{INTRODUCTION}

In cases of mastitis, milk yield of the infected quarter behaves differently than uninfected quarters. In noninfected quarters, inflammation is not present but milk production might be affected by the systemic illness; for example, due to the loss of appetite and energy consumption during the immune reaction (RajalaSchultz et al., 1999; Blowey and Edmondson, 2000; Gröhn et al., 2004). The milk losses of the infected quarter are influenced by both systemic and local effects; these local effects are related to the inflammatory reaction, damage of the tight junctions in the udder tissue and the pathogen toxins (Zhao and Lacasse, 2008). As such, monitoring milk losses at quarter level has large potential for gaining insight into different (udder health-related) physiological problems. One of the main challenges when monitoring milk yield dynamics and losses is having a reliable reference to which the measured yield can be contrasted. Previous research has focused mostly on yield at udder level, often averaged per day or per week (Gröhn et al., 2004; Wilson et al., 2004) or predicted for a whole 305-d lactation period either based or not on a limited number of test day yields (overview in Ehrlich, 2013). To predict on a short-term horizon, an extrapolation of a nonlinear lactation model can be used (Huybrechts et al., 2014). An overview of the available lactation models are given in Dematawewa et al. (2007); however, this approach becomes uninformative once the normal course of the curve is disrupted, and does not take variability caused by differing milking intervals (MI) into account, which is important in automated milking systems. Gasqui and Trommenschlager (2017) recently developed a physiology-based model to predict udder yield at milking session level, but this white-box model is rather complex and requires theoretical assumptions and further data-based testing. To our knowledge, no specific models have been proposed for short-term (1 to $50 \mathrm{~d}$ ) 
predictions of milk yield at quarter level of individual cows based on real data.

Linear mixed models (LMM) provide a framework to study the relation between a continuous dependent variable and different independent covariates, both fixed and random. The fixed effects covariates describe the average trend in the data over all subjects. The random effect covariates describe the deviation of each individual subject from this average trend. In LMM, both fixed and random covariates are linear in their parameters. Besides obtaining insight in general and individual trends in the data, the LMM framework can also be used to predict the dependent variable for an individual subject using empirical Bayes techniques, whereby a prior distribution of is calculated based on an available data set. The marginal model defined by the fixed effects describes the average trend in the data, whereas the variance-covariance matrix represents how the different random effects relate to each other in individual subjects. The overall methodology allows for comparing the predicted with the measured variable and enables us to gain insight in its dynamics during disruptions. For more details on the general framework of linear mixed models, we refer to Verbeke and Molenberghs (1997).

The current paper presents a novel methodology to describe and predict future quarter milk yield (QMY) at the milking session level for short periods of at most $50 \mathrm{~d}$ using a LMM approach. We further refer to the developed framework as quarter-level mixed model (QLMM) and to the QMY over time at quarter level as quarter lactation (QL). The QMY predictions obtained through the QLMM can be used as a reference for milk loss calculations post hoc; for example, during periods of clinical mastitis or other diseases. Moreover, the QLMM can be used to describe the QMY in unperturbed state and compare dynamics over time or perform on-line comparisons each time a new data point becomes available. Ultimately, this allows us to calculate, for example, the yield dynamics during infection, which by monitoring at quarter level could provide the farmers with ad hoc estimations of recovery and cure.

\section{MATERIALS AND METHODS}

\section{Data Selection}

The QLMM was developed using a data set of 504 lactations collected between November 2005 and October 2014 on the test farm Hooibeekhoeve in Geel, Flanders, Belgium (DS1). Another data set collected in 2016 and 2018 was used for the external validation (DS2). Data in between were excluded because of sensor malfunctioning. Cows were milked with an automated milking system from DeLaval (VMS; Tumba, Sweden), equipped with 4 ICAR-approved MM25 milk meters to measure QMY. Only lactations for which milk yield of at least $200 \mathrm{~d}$ starting from the parturition date was available were included, leaving 375 lactations in DS1 and 84 lactations in DS2 (Table 1). In the period toward drying off, the fetus's energy demand increases and milk yield is gradually inhibited. Because exact insemination dates were not available and, therefore, these effects could not be taken into account reliably, the data of each lactation were cutoff at d 305 when the cows were up to 8 mo pregnant.

The QLMM describes the QMY during the normal course of lactation; that is, without significant drops in QMY caused by external factors, such as disease. More specifically, its purpose is to describe a quarter's milk production potential. Thereby, we explicitly assumed that the Wood model can accurately describe a normal quarter's milk production in the first $305 \mathrm{~d}$ after calving. Moreover, it is very difficult to know the real health status of a cow, and the available disease logbook did not give satisfactory explanations for all milk yield drops. For these reasons, a data-based, generally applicable curve selection procedure was preferred. This selection procedure can be used without a need for intensive health monitoring and, more importantly, it

Table 1. Two data sets with unperturbed quarter lactations were selected using a 3 -step procedure, based on the availability of enough data (criterion 0) and the presence of perturbations (criteria 1 and 2)

\begin{tabular}{|c|c|c|c|c|c|c|c|}
\hline Criterion & $\begin{array}{l}\text { Udder/quarter } \\
\text { level }\end{array}$ & \multicolumn{3}{|c|}{ Data set 1} & \multicolumn{3}{|c|}{ Data set 2} \\
\hline (1) Separated milkings - EC & Udder level & 772 & 728 & 36.1 & 84 & 252 & 33.7 \\
\hline (2) Milk yield drops & Quarter level & 347 & 381 & 18.9 & 126 & 126 & 16.8 \\
\hline Total & & 1,635 & 381 & 18.9 & 622 & 126 & 16.8 \\
\hline
\end{tabular}

${ }^{1} \mathrm{QL}=$ quarter lactation: milkings of 1 quarter over time.

${ }^{2} \mathrm{EC}=$ electrical conductivity. 


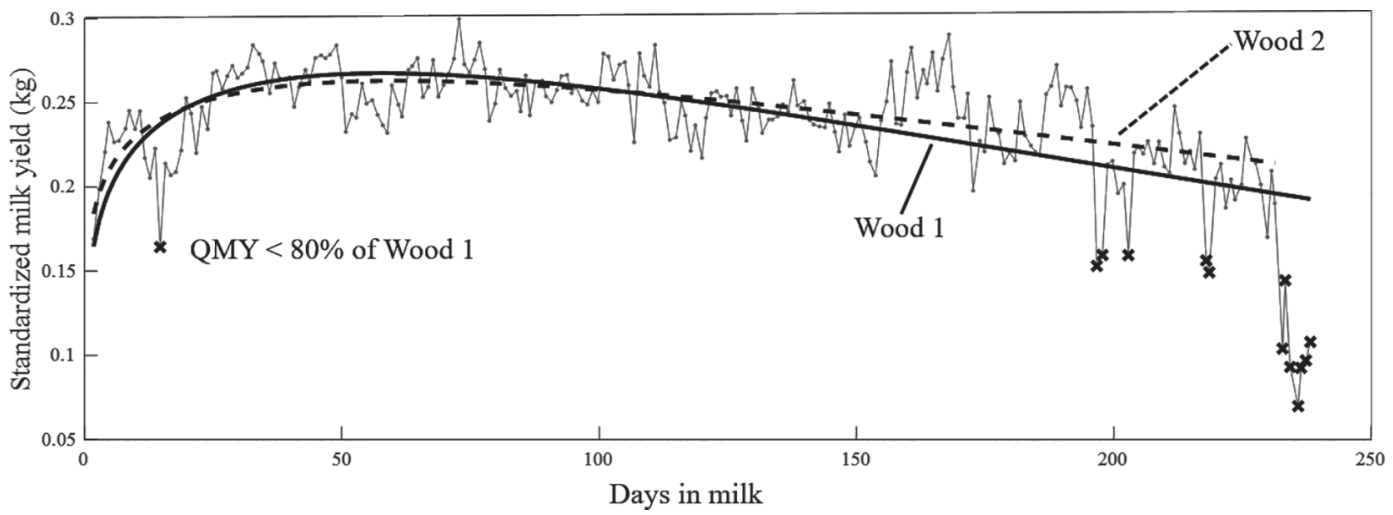

Figure 1. Second step of the selection procedure entailed the detection of significant drops in milk production at quarter level. Because milking interval effects are not of interest here, standardized daily milk yield (in $\mathrm{kg} / \mathrm{h}$ ) was used. First, the solid model was fitted using all the data. The crossed standardized milk yields were below $80 \%$ of the expected yields. In the second step, these are discarded to fit the second Wood model, where after quarter level having milkings below $80 \%$ of the fitted curve for more than 4 successive days were excluded from the analysis. $\mathrm{QMY}=$ quarter milk yield.

yields a data set of QL without perturbations. As such, we applied two criteria, the first at udder level, the second at quarter level. (1) No milk was separated for more than 9 successive milkings (i.e., $4 \mathrm{~d}$ on average), and no periods in which the electrical conductivity of a quarter was larger than $110 \%$ of the mean of the other quarters for a period longer than 9 milkings were present. (2) No dips in which the standardized daily milk yield was less than $80 \%$ of the expected standardized daily milk yield for $4 \mathrm{~d}$ or longer were detected. In contrast to the QMY used in the rest of the manuscript, the patterns caused by a varying MI were not of interest here. Therefore, the standardized yield used in this selection step was calculated as QMY summed per day and divided by the sum of the corresponding MI. For example, when the cow is milked 3 times on a certain day, at 0200,0900 , and $2100 \mathrm{~h}$ with milking intervals of, respectively, 10, 7, and $12 \mathrm{~h}$ and yields of 9,7 , and $12 \mathrm{~kg}$, the standardized daily yield is $28 \mathrm{~kg} / 29$ $\mathrm{h}=0.96 \mathrm{~kg} / \mathrm{h}$. The second criterion entailed a 2 -step procedure. First, a nonlinear Wood model (equation 1; Wood, 1967) was fitted on all the standardized daily milk yield data at quarter level. In equation 1 (Wood1), $\beta_{0}, \beta_{1}$, and $\beta_{2}$ are the parameters of the Wood model:

$$
\text { Standardized daily yield }=\beta_{0} \times e^{-\beta_{1} \times \mathrm{DIM}} \times \mathrm{DIM}^{\beta_{2}} \cdot[1]
$$

In this first step, large individual deviations in standardized daily yield have an undesirable effect on the fit. Therefore, the days for which the standardized yield was below $80 \%$ of the expected yield (Wood1) for that QL were discarded and a second Wood model (Wood2) was fitted on the cleaned data (see also Figure 1). The selection of the QL that were further used to build the
QLMM was performed based on the absence of periods in which the standardized daily yield was below $80 \%$ of the expected yield (Wood2) for $4 \mathrm{~d}$.

Using these 2 selection criteria, 381 QL originating from 98 cows during 136 lactations were selected for DS1 and 126 QL from 59 unique cows and 64 lactations were selected for DS2. An overview of the number of QL excluded per criterion is shown in Table 1.

Each QL was assigned to a position (POS) and parity (PAR) class, based on its position in the udder (front, POS1 vs. hind, POS2) and the parity of the cow (first parity, PAR1 vs. multiparous cows, PAR2). The final DS1 contained 87 front and 103 hind QL originating from a first-parity cow, and 96 and 95 QL originating from a front and hind quarter of a multiparous cow, respectively. For DS2, this was 43 front and 37 hind QL from first-parity cows, and 20 front and $26 \mathrm{QL}$ from higher-parity cows. Milkings with MI less than 6 or more than $24 \mathrm{~h}$, or in which QMY was less than $0.5 \mathrm{~kg}$, were excluded from the analysis (3.51 and 5.5\%, respectively, for DS1 and DS2). In total, the QMY of 290,495 milkings was used for model development, whereas the external validation performed on DS2 was done using 99,279 milkings.

\section{Model Development and Selection}

The basis for the developed QLMM is the linearized Wood model (equation 2), complemented with factors known to influence QMY, either dependent or not on POS, PAR, or both. Using a linearized version of the model allows for simplifying the model calculations while maintaining physiological interpretability of the parameters: 


$$
\begin{gathered}
\ln (\mathrm{QMY} \cdot 1,000)=\beta_{0}+\beta_{1} \cdot \mathrm{DIM} \\
+\beta_{2} \cdot \ln (\mathrm{DIM}) .
\end{gathered}
$$

The QMY is converted to grams to avoid QMY of less than $1 \mathrm{~kg}$ having a strong effect on the fit and goodness-of-fit measures after linearization. In addition to the parameters inherent to the Wood model $\left(\beta_{0}, \beta_{1}\right.$, and $\beta_{2}$ ), the MI and its interactions with time were also included and tested during model development. The way MI was entered in the models was derived from a preliminary model and exploration step, not further described in this paper. In short, MI was expressed in hours and included as the natural logarithmic transformation of MI (MI'). During longer MI, more milk is produced, but when the udder fills this effect will be inhibited by the physical limitation of space in the udder cisternae. The size of this effect of the MI might depend on the DIM (Ouweltjes, 1998; Bruckmaier et al., 2001; Hogeveen et al., 2001; Penry et al., 2018).

The QLMM was fitted to the data of DS1 considering each of the $381 \mathrm{QL}$ as independent subjects, thus ignoring the cow level, as the QMY is not only subject to cow factors, such as the production potential or farm management, but also depends on individual quarter effects. For example, the udder conformation reflected in quarter asymmetry or factors such as scar tissue resulting from previous mastitis cases might influence QMY. Here, we chose not to take the cow into account because this would require a nested, 2-level random effect. We considered the increased intuitiveness in this case as not outweighing additional complexity and computational load.

To cover the biological variability among the $\mathrm{QL}, 4$ random factors were included in the QLMM: 1 for each of the 3 covariates of the Wood model [corresponding to the intercept, DIM, and $\ln (\mathrm{DIM})]$, and 1 for the MI' covariate. Inclusion of the MI' covariate as a random factor is supported by the large differences in effect of MI on yield between cows (e.g., Ouweltjes, 1998; Hogeveen et al., 2001).

The general form of the QLMM is shown in equation 3 , in which $Y_{i}$ is the QMY for subject $i$ (i.e., each QL, N in total), $X_{i}$ are the known fixed effect covariates [intercept, DIM, $\ln (\mathrm{DIM}), \mathrm{MI}$ ', POS, PAR], and $\boldsymbol{\beta}$ the vector of fixed effect parameters to be estimated. Similarly, $Z_{i}$ are the random effect covariates [intercept, DIM, $\ln (\mathrm{DIM})$, and $\left.\mathrm{MI}^{\prime}\right]$ and $\mathbf{b}_{i}$ the vector of random effect parameters for each subject (QL) $i$. In general, the fixed effects represent the average trends in the data, whereas the random effects represent the deviation of each individual subject from this average structure for certain covariates. The random effect parameters $\left(\mathbf{b}_{i}\right)$ and the residual errors $\left(\varepsilon_{i}\right)$ are assumed to be drawn from a normal distribution with mean vector $\mathbf{0}$ and covariance matrix $\mathbf{D}$ and $\boldsymbol{\Sigma}_{i}$, respectively. The latter $\left(\boldsymbol{\Sigma}_{i}\right)$ is assumed to be a diagonal matrix with constant residual variance (i.e., $\boldsymbol{\Sigma}_{i}=\sigma^{2} \mathbf{I}$ ). The variance covariance matrix $\mathbf{D}$ is taken unstructured, meaning that a separate variance component is estimated for each random effect, as well as a separate covariance component between each pair of random effects:

$$
\left\{\begin{array}{rl}
Y_{i}= & X_{i} \boldsymbol{\beta}+Z_{i} \mathbf{b}_{i}+\varepsilon_{i} \\
& \mathbf{b}_{i} \sim N(0, \mathbf{D}) \\
\varepsilon_{i} & \sim N\left(0, \boldsymbol{\Sigma}_{i}\right) \\
\mathbf{b}_{1}, \ldots, \mathbf{b}_{N}, \varepsilon_{1}, \ldots, \varepsilon_{N} \text { independent }
\end{array} .\right.
$$

To find the best model relating the QMY to DIM, $\ln (\mathrm{DIM}), \mathrm{MI}$ ', POS, and PAR, 81 different models covering all meaningful combinations of these covariates and their interactions were fitted to the data set of 381 unperturbed QL using the maximum likelihood method (REML). These 81 models yielded goodness-of-fit statistics that were used to find the model best describing the data. As goodness-of-fit indicators, Akaike's information criterion (AIC), the Bayesian information criterion, the $\mathrm{R}_{\text {adjusted, }}^{2}$ and the average mean proportional error (MPE) were used. The AIC, Bayesian information criterion, and $\mathrm{R}_{\text {adjusted }}^{2}$ were taken as computed in the software and average MPE was calculated as shown in eq. 4 ,

$$
\mathrm{MPE}=\frac{\sum_{i=1}^{N}\left(\left|Q M Y_{i, j}-\widehat{Q M Y}_{i, j}\right| / Q M Y_{i, j}\right) \times 100}{N},
$$

with $\widehat{Q M Y}_{i, j}$ the exponentiated predicted QMY for QL $i$ at milking $j$. All models and derived statistics were fitted using Matlab (R2017a, Mathworks Inc., Natick, MA).

\section{Quarter Milk Yield Predictions}

The advantage of using a mixed model is that future QL can be predicted for an individual cow based on an incomplete QL curve of that cow and an historical data set of QL of other cows. To do so, empirical Bayes techniques are used to estimate the random effects for the QL of that particular cow. The random effects of a new QL are calculated as follows (equation 5):

$$
\widehat{b_{i}}=\mathbf{D} Z_{i}^{\prime} \mathbf{W}_{i}\left(\mathbf{y}_{i}-X_{i} \boldsymbol{\beta}\right),
$$


with matrix $\mathbf{W}_{i}$ denoting the total variance-covariance structure, calculated as $\mathbf{W}_{i}=\left(Z_{i} \mathbf{D} Z_{i}^{\prime}+\boldsymbol{\Sigma}_{i}\right)^{-1}$, where $\boldsymbol{D}$, $Z_{i}, X_{i}, \boldsymbol{\beta}$, and $\boldsymbol{\Sigma}_{i}$ as defined before. The $\mathbf{y}_{i}$ are the measurements of the new subject, so that $y_{i}-X_{i} \boldsymbol{\beta}$ is the deviation of the new subject's data from the fixed effects model. In our case, $\mathbf{y}_{i}$ is the vector of available QMY for the new QL. Once the predictions are obtained, the residuals can then be used to estimate milk losses or to describe QMY dynamics.

Because we are interested in the accuracy of the QLMM to predict QMY during the normal course of lactation, we used 2 validation steps in which we compared the predicted with the measured QMY. The first validation was a cross validation, where we randomly assigned two-thirds of the QL of each PAR and POS combination to a training set and the remaining third to a test set, taking into account the lactation from which they originated. More specifically, all QL of 1 lactation (i.e., maximum 4) were assigned to either the training set or the test set to avoid data of the same lactation residing in both. This process was repeated 10 times and, as such, we obtained 10 validation splits, each consisting of a training and test set. Next, we fitted the QLMM on the training set to estimate the fixed effect parameters $(\boldsymbol{\beta})$, the random effect variance-covariance matrix $(\mathbf{D})$, and the residual variance $\left(\boldsymbol{\Sigma}_{i}\right)$. This allowed for each QL in the test set to compute the random effect $\hat{b}_{i, k}$ according to equation 5, and thus to produce the future QMY values. The second validation was an external validation, in which the prior distribution of the model fitted on DS1 was used to predict QMY for each of the QL in DS2.

To investigate the effect of the availability of QMY data on the accuracy of predictions, the QL of the test sets and DS2 were cut after 10, 15, 20, 30, 40, 65, 115, 165,215 , and $265(k)$ days. The QMY of the milkings $j$ in the following $50 \mathrm{~d}$ (so up to $50 \mathrm{~d}$ after the last QMY presented to the model) were then predicted as shown in equation 6 . We chose $50 \mathrm{~d}$ to show the use of the model on short term because, for most infections causing clinical mastitis, the direct pathogen effect should be eliminated by then. Investigating the validity of the model for longer predictions ahead should be subject to further research:

$$
\widehat{Q M Y}_{i, j, k}=X_{i, j, k} \boldsymbol{\beta}+Z_{i, j, k} \hat{b}_{i, k}
$$

with $X_{i, j, k}$ and $Z_{i, j, k}$ the fixed and random effect covariates respectively for each QL at the jth milking after the $k$ th day. To evaluate the prediction accuracy, the MPE and mean absolute error (MAE) was calculated as in equations 7 and 8 , respectively, averaged over all milkings (Nmilkings) of each day after $k$,

$$
\mathrm{MPE}=\frac{\sum_{N \text { milkings }}\left(\left|Q M Y_{i, j, k}-\widehat{Q M Y}_{i, j, k}\right| / Q M Y_{i, j, k}\right) \times 100}{N \text { milkings }}
$$

and

$$
\text { MAE }=\frac{\sum_{N \text { milkings }}\left(\left|Q M Y_{i, j, k}-\widehat{Q M Y}_{i, j, k}\right|\right)}{N \text { milkings }} .
$$

To illustrate the potential of the proposed QLMM, we included 2 examples for which quarter-level milk losses were estimated during 2 cases of clinical mastitis $\left(\mathbf{Q L}_{\mathrm{CM} 1}\right.$ and $\left.\mathbf{Q L}_{\mathrm{CM} 2}\right)$. For both third-parity cows, clinical mastitis was detected in the right hind quarter (POS2, PAR2) on d 33 and 97, respectively. Bacteriological research was performed on the day of detection in the milk control center of Flanders, MCC-Vlaanderen, Lier, Belgium (Supré et al., 2014). In $\mathrm{QL}_{\mathrm{CM} 1}$, Escherichia coli was identified as the causal pathogen, and the infected quarter dried up on d 43, $10 \mathrm{~d}$ after detection. The second example consisted of a rather mild case of clinical mastitis caused by gram-positive Corynebacterium bovis bacteria. Besides some flocks in the milk, this cow showed no clinical symptoms and the antibiotic treatment succeeded to clear the infection in $4 \mathrm{~d}$.

In a first step, the mixed model parameters were estimated using all available data of healthy QL (Tables 2 and 3). Next, all data of the $\mathrm{QL}_{\mathrm{CM}}$, up to $5 \mathrm{~d}$ before detection (i.e., d 28 and 92, respectively, for $\mathrm{QL}_{\mathrm{CM} 1}$ and $\mathrm{QL}_{\mathrm{CM} 2}$ ), were used to calculate the random effects according to equation 5. Similarly, the QMY up to the same day of the QL of the symmetric counterpart (left hind quarter) of those 2 infected quarters, denoted as noninfected $\mathrm{QL}_{\mathrm{NI} 1}$ and $\mathrm{QL}_{\mathrm{NI} 2}$, were used to estimate the random effects of these counterparts. Milk losses were then calculated as $Q M Y_{i, j, k}-\widehat{Q M Y}_{i, j, k}$, with $i$ denoting the intended $\mathrm{QL}, j$ the milkings of the period over which milk losses were calculated (which was set to $21 \mathrm{~d}$ ), and $k$ denoting the number of days used for calculation of the random effect (i.e., 28 and 92).

\section{RESULTS AND DISCUSSION}

\section{Data, Model, and Goodness-of-Fit}

As the included covariates were chosen after an preliminary model and data exploration phase, which is not described in detail in the current paper, all tested models fitted the data set well. However, the best 4 models all included an interaction effect between DIM 
Table 2. Final model fixed effect covariates and corresponding parameter names, estimates and $P$-values

\begin{tabular}{llrc}
\hline Covariate $^{1}$ & Parameter & Estimate $(\beta)$ & $P$-value \\
\hline Intercept & $\beta_{0}$ & 5.3934 & $<0.001$ \\
POS2 & $\beta_{1}$ & 0.0312 & $<0.001$ \\
PAR2 & $\beta_{2}$ & 0.2155 & $<0.001$ \\
POS2 $\times$ PAR2 & $\beta_{3}$ & 0.1975 & $<0.001$ \\
DIM & $\beta_{4}$ & -0.0039 & $<0.001$ \\
DIM $\times$ PAR2 & $\beta_{5}$ & -0.0011 & $<0.001$ \\
$\ln ($ DIM) & $\beta_{6}$ & 0.8240 & $<0.001$ \\
$\ln ($ DIM) $\times$ POS2 & $\beta_{7}$ & 0.0458 & $<0.001$ \\
MI' & $\beta_{8}$ & 0.8240 & $<0.001$ \\
MI' $\times$ DIM & $\beta_{9}$ & 0.0005 & $<0.001$ \\
\hline
\end{tabular}

${ }^{1}$ PAR2 is the additional effect estimated for quarter lactations belonging to the second parity class, originating from second or higher parity cows; POS2 is the additional effect estimated for quarter lactations from hind quarters; MI' is milking interval covariate.

and parity, $\ln (\mathrm{DIM})$ and quarter position, and MI' and DIM. They differed in the dependence of the other covariates. In Table 2 , the final best model's estimates for the fixed effects and related $P$-values are listed. Table 3 shows the variance-covariance matrix $\mathbf{D}$ of the random effects. The final model, from which the marginal part is shown in equation 9, has an average MPE of $8.48 \%$ (retransformed QMY) and an $\mathrm{R}_{\text {adjusted }}^{2}$ of 0.878 . The residual variance $\sigma^{2}$ is $0.0168 \mathrm{~kg}$. This result is similar to the model fit obtained with the physiology-based model of Gasqui and Trommenschlager (2017) for milk production on udder level on a milking session basis. When fitting an individual nonlinear Wood model for each QL, without taking any of the other covariates into account, we could only reach an MPE of $17.5 \%$ :

$$
\begin{gathered}
\ln (\mathrm{QMY})=\beta_{0}+\beta_{1} \times \mathrm{POS}+\beta_{2} \times \mathrm{PAR} \\
+\beta_{3} \times \mathrm{POS} \times \mathrm{PAR}+\beta_{9} \times \mathrm{DIM}+\beta_{4} \times \mathrm{PAR} \\
\times \mathrm{DIM}+\beta_{5} \times \ln (\mathrm{DIM})+\beta_{6} \times \mathrm{POS} \times \ln (\mathrm{DIM}) \\
+\beta_{7} \times \mathrm{MI}^{\prime}+\beta_{8} \times \mathrm{MI}^{\prime} \times \mathrm{DIM}+e .
\end{gathered}
$$

In this best fitting model, the initial QMY is dependent both on PAR and POS. The positive estimate for second and higher parities means that the QMY of these QL at the start of the lactation is significantly higher than that of first-parity cows. More specific, for cows of second and higher parity, QMY at the start of the lactation is, on average, $3.4 \%$ higher per quarter than for first-parity cows. This can be explained by the fact that the udder tissue is not yet fully developed at the start of the first lactation in most cows (Dijkstra et al., 1997). Moreover, the QMY of hindquarters is significantly higher from the front quarters at the start of the lactation. The DIM covariate mainly affects the slope of the second part of the lactation and is thus indicative for the persistency of the QMY. This slope also depends on the parity, and higher-parity cows have a steeper slope than first-parity cows $(P<0.001)$, also reported by Dematawewa et al. (2007). The dynamics of the QMY in the first part of the lactation before the milk yield peak are mainly influenced by the $\ln (\mathrm{DIM})$ covariate. In the best model, $\ln (\mathrm{DIM})$ depends on POS. Here, the increase in QMY of the hindquarters is steeper than that of the front quarters, which was expected, as the peak yield of front quarters is typically lower. The MI' has a significant positive effect on QMY and seems to gain importance over time.

Considering each QL as an independent subject allowed us to account for the variability in QMY between (e.g., the 2 front or hindquarters of the same cow). In principle, one would expect that first a random cow effect is estimated to cover (e.g., genetic predisposition for milk production) and, next, an effect of quarter within cow is added to allow within-cow variability. This alternative approach requires a nested mixed model, which increases the complexity and estimation procedure. Therefore, it was not considered here but might be investigated in the future as an extension of the currently proposed QLMM.

In this work, a data-based selection procedure was preferred above selection of the curves based on a real health status of the cow. We did so because this procedure allows us to apply the selection step on each available data set of a farm with an automated milking system and because the real health status is not always known. However, the procedure was shown to be quite strict, excluding all QL with dips in yield lasting longer than $4 \mathrm{~d}$, caused by udder health or other problems or not. This might cause a bias toward selection of QL of more robust cows. The effect of a less-strict selection procedure should be further investigated. Milkings later than $305 \mathrm{~d}$ were also not included in the analysis because of the increasing effect of a growing fetus, causing the milk yield to drop at the end of a lactation. Because milk yields of the first $305 \mathrm{~d}$ are generally seen as the most interesting to monitor, and problems hereafter often resulting in dry off, this is not seen as a problem; however, eventually the current model might

Table 3. Variance-covariance matrix of the random effects, D

\begin{tabular}{lrrrr}
\hline $\mathbf{D}$ & Intercept & \multicolumn{1}{c}{ DIM } & $\ln (\mathrm{DIM})$ & $\mathrm{MI}^{11}$ \\
\hline Intercept & 0.1330 & & & \\
DIM & 0.0002 & $1.23 \times 10^{-6}$ & & \\
$\ln (\mathrm{DIM})$ & -0.0201 & $-6.64 \times 10^{-5}$ & 0.0062 & \\
MI $^{1}$ & -0.0163 & $1.03 \times 10^{-6}$ & 0.0003 & 0.0061 \\
\hline
\end{tabular}

${ }^{1}$ Milking interval covariate. 
be extended with an effect of pregnancy in the future if seen appropriate.

\section{Quarter Milk Yield Predictions}

Using the model from Tables 2 and 3 and the estimate for the residual error, QL can be predicted for future DIM. At the start of a new lactation, no QMY is recorded yet and no information is available for QL $i$. The best guess for predicting the future QMY at that moment is based on the fixed effects only. In the future, information on, for example, genetically similar cows or previous lactations might be added, but this was not the focus in the present study. Once a QMY is observed, the random effect for that QL can be estimated through equation 5 and predictions will improve with increasing number of lactation days $(k)$. The accuracy of the QMY prediction will also depend on how far in the future QMY is predicted, with the expectation that it is more difficult to perform long time ahead predictions (larger $j$ ).

The average MPE and MAE over all validation splits are given in the upper left and right panel of Figure 2, respectively, whereas the results for the external validation on DS2 are given in the lower panels. As the results of both validations are very similar, no distinction will be made in the next discussion.

As expected, the further ahead the prediction, the larger the prediction error. Using only 10 and $15 \mathrm{~d}$ of input data results in the largest errors, although the MPE in the first $12 \mathrm{~d}$ stays below $12 \%$ for each amount of input data $k$ independent of the validation data set. This performance is relatively good given the fact that the error on the output of the MM15 milk meters can already be as high as 7\% (ICAR, 2014). Taking into account this measurement uncertainty and the fact that the QMY might be influenced by other factors, such as estrus, the environmental conditions, feed, concentrate supplementation, and unknown diseases, an MPE of 8 to $20 \%$ is considered a sufficiently good result. More specifically, these errors mean that when the actual QMY is $5 \mathrm{~kg}$ of milk the model prediction lies between 4.6 and $5.4 \mathrm{~kg}$ in the best and 4 and $6 \mathrm{~kg}$ in the worst case. Comparing absolute errors, predictions of future QMY are comparable to when more than $65 \mathrm{~d}$ of input data (i.e., after peak milk yield) is used. On average, MAE is between 0.25 and $0.65 \mathrm{~kg}$ per quarter and per milking. The external validation shows that, although these data are collected a few years later than the training set, moment of collection seems not to influence prediction performance.

To illustrate a possible use of the QLMM, 2 examples of milk loss calculations are presented: one for a severe
$\left(\mathrm{QL}_{\mathrm{CM} 1}\right)$ and one for a mild $\left(\mathrm{QL}_{\mathrm{CM} 2}\right)$ case of clinical mastitis and the healthy counterparts $\left(\mathrm{QL}_{\mathrm{NI} 1}\right.$ and $\mathrm{QL}_{\mathrm{NI} 2}$ ) of the infected udder quarter. In Figure 3, the residuals of the model (i.e., the milk losses) are shown for both cases.

In the period before the diagnosis, the model showed a very close fit to the data, shown by residuals varying around zero for both cases. Based on the period before the detection, the random effects of these cows were calculated. In the severe mastitis case, the QMY dropped suddenly on the day of detection for both the $\mathrm{QL}_{\mathrm{CM} 1}$ and $\mathrm{QL}_{\mathrm{NI} 1}$. In total, milk losses summed to 344 and $176 \mathrm{~kg}$ for $\mathrm{QL}_{\mathrm{CM} 1}$ and $\mathrm{QL}_{\mathrm{NI} 1}$ over a period of $21 \mathrm{~d}$, respectively. The milk losses in the noninfected quarter could most likely be attributed to the systemic illness of the cow reflected in, for example, decreased appetite and the energy required for the inflammation reaction (Blowey and Edmondson, 2000). The infected quarter dried $10 \mathrm{~d}$ after detection and the $\mathrm{QMY}$ of $\mathrm{QL}_{\mathrm{NI} 1}$ increased again to normal levels. Although the QMY in the noninfected quarter clearly increased after $\mathrm{d} 7$ from detection, the milk yield of this cow did not seem to have fully recovered by $\mathrm{d} 21$. In general, the pattern and losses obtained here are very similar to those reported by Gröhn et al. (2004), who found mean daily losses of total milk yield from 13 to $4 \mathrm{~kg} / \mathrm{d}$, averaging $170 \mathrm{~kg}$ over $21 \mathrm{~d}$ in the case of an E. coli infection. Similar to our observations, those authors also noticed a sudden drop at the day of detection, whereby no milk losses are noted before that day.

The mild case differed in many aspects from the severe case, namely (1) the infection seemed to affect the cow's QMY already before the actual detection by the herdsman; (2) the total milk loss in the 21-d reference period was only $43 \mathrm{~kg}$ for the infected quarter; and (3) a positive residual $(35 \mathrm{~kg})$ was observed for the QLNI2. The latter might be the result of a redistribution in the nutrients by which the milk losses were partly compensated. In contrast to the severe case, the QMY of the $\mathrm{QL}_{\mathrm{CM} 2}$ seems to have fully recovered by d 14 after detection, confirmed by absence of clinical symptoms and no bacteria present in the quarter.

As shown by these examples, application of the QLMM methodology on farm might provide a more reliable estimate of the QMY at session level. Accordingly, we identified at least 2 possible uses of the QLMM, post hoc and on-farm estimations of milk loss and milk yield dynamics during infection. The first (post hoc) can, for example, facilitate further research into the link between quarter yield dynamics and the causal agents or recovery of the infection. For the second, the QLMM might also be integrated in on-line monitoring algorithms in which information of the first 

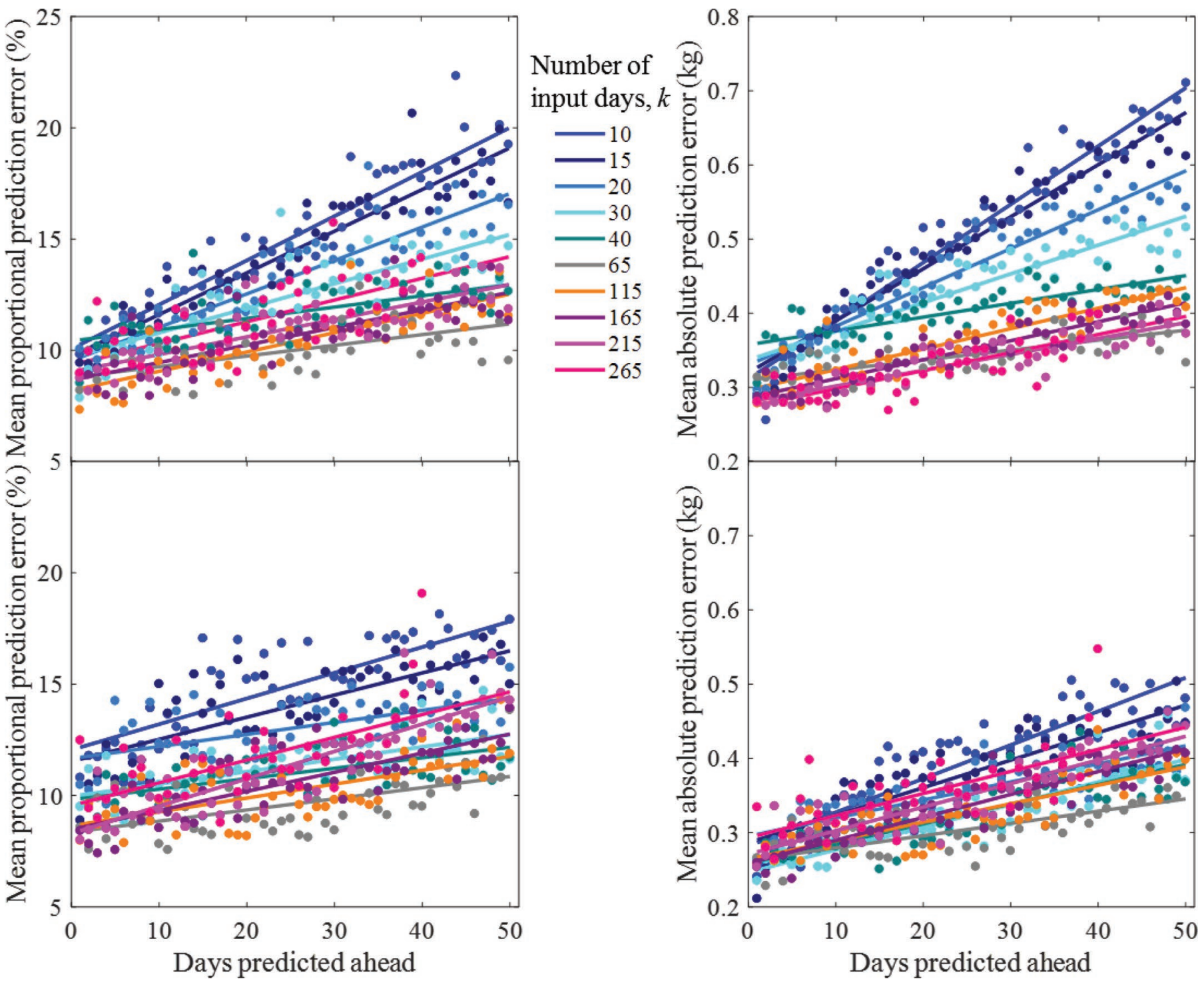

Figure 2. Mean proportional prediction errors (left) and mean absolute prediction errors (right) for healthy quarters predicting quarter milk yield of 1 to $50 \mathrm{~d}$, using 10 to $265 \mathrm{~d}$ of input data $(k)$. In the upper panels, the results of the $2 / 3$ to $1 / 3$ cross validation are presented, whereas in the lower panels the results for the external validation on a new data set of the same farm are shown. For example, quarter milk yield was predicted d 11 to 60 using $10 \mathrm{~d}$ of input data. As expected, the prediction error increased when predicting further ahead in time (j), but even when using only $10 \mathrm{~d}$ of input data and predicting up to $50 \mathrm{~d}$, the mean proportional prediction error stayed below $20 \%$. The lighter the color, the more data were used to estimate the random effect; accordingly, the further ahead in the lactation quarter milk yield was predicted. Color version available online.

can possibly be integrated. More specifically, following recovery and cure during an udder health problem becomes possible; for example, by comparing the predicted milk yields with the measured ones at the quarter level and following the dynamics of the residuals. Once the prior distribution of the model is estimated on a historical data set of a specific farm, the QMY of each new milking might be compared with its prediction. After detection of a problem, either using the QLMM or not, QMY dynamics can then provide information on the evolution of the problem by comparing quarters among the predicted yield, but also among each other. Ultimately, this will lead to better-founded, objective treatment and management decisions.

The QLMM method presented was developed on a data set originating from a single farm. This limited data set does not allow us to make strong statements on its general validity. Therefore, it should be further tested on more farms and different milking systems. However, because of its generality, the proposed QLMM 

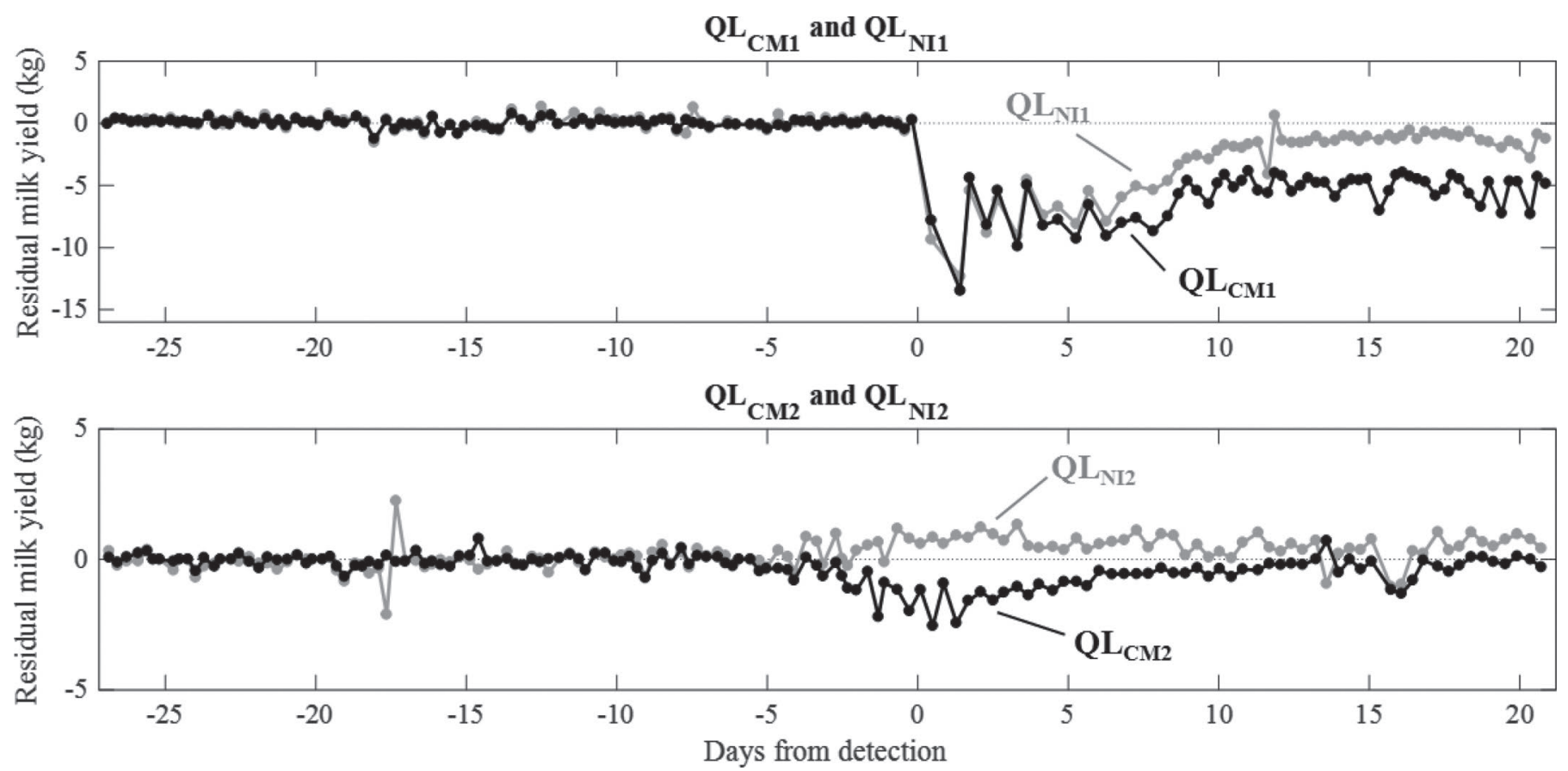

Figure 3. Quarter milk yield (QMY) residuals for quarter lactations (QL), for which QMY was predicted during a case of severe (left) and mild (right) clinical mastitis (CM1 and CM2, respectively) and the symmetric uninfected counterpart $\left(\mathrm{QL}_{\mathrm{NI} 1}\right.$ and $\left.\mathrm{QL}_{\mathrm{NI} 2}\right)$. In the severe case, both the infected and noninfected quarter suffered significant losses. The losses of the mildly infected quarter were partly compensated in the noninfected counterpart, probably through nutrient repartitioning.

method provides a very valuable tool for researchers for use in mastitis research and offers leverage for better understanding the influence of disease on QMY.

\section{CONCLUSIONS}

We developed a novel method for the prediction of quarter-level milk yield on a milking session basis for healthy cows. This method allowed for short-term prediction of the reference yield and, accordingly, investigation of milk losses and yield dynamics after perturbations. It was shown that this methodology holds a lot of potential as the average error on the milk yields forecasted $50 \mathrm{~d}$ ahead is between 8 and $20 \%$, being only between 8 and $15 \%$ when considering predictions of $21 \mathrm{~d}$. However, although this method is assumed to be robust based on its physiological basis, further validation on more farms is needed. Once it has been extensively validated, the QLMM has potential to become a valuable tool for milk loss estimation, genetic phenotyping, pathogen research, immune and resilience studies, among others.

\section{ACKNOWLEDGMENTS}

Ines Adriaens and Ben Aernouts were supported by the Fund for Scientific Research (FWO) Flanders
(Brussels, Belgium), grant number 11ZG916N and 12K3916N, respectively. Tjebbe Huybrechts was fellow of the Institute for the Promotion of Innovation through Science and Technology in Flanders, Brussels, Belgium (IWT, SB grant 121611).

\section{REFERENCES}

Blowey, R., and P. Edmondson. 2000. Mastitis Control in Dairy Herds. 2nd ed. Farming Press, United Business Media, Sovereign House, Tonbridge, UK.

Bruckmaier, R. M., J. Macuhova, and H. H. D. Meyer. 2001. Specific aspects of milk ejection in robotic milking: A review. Livest. Prod. Sci. 72:169-176. https://doi.org/10.1016/S0301-6226(01)00277-9.

Dematawewa, C. M. B., R. E. Pearson, and P. M. Vanraden. 2007. Modeling extended lactations of Holsteins. J. Dairy Sci. 90:39243936. https://doi.org/10.3168/jds.2006-790.

Dijkstra, J., J. France, M. S. Dhanoa, J. A. Maas, M. D. Hanigan, A. J. Rook, and D. E. Beever. 1997. A model to describe growth patterns of the mammary gland during pregnancy and lactation. J. Dairy Sci. 80:2340-2354. https://doi.org/10.3168/jds.S0022 -0302(97)76185-X.

Ehrlich, J. L. 2013. Quantifying inter-group variability in lactation curve shape and magnitude with the MilkBot ${ }^{\circledR}$ lactation model. PeerJ 1:e54. https://doi.org/10.7717/peerj.54.

Gasqui, P., and J. M. Trommenschlager. 2017. A new standard model for milk yield in dairy cows based on udder physiology at the milking-session level. Sci. Rep. 7:8897. https://doi.org/10.1038/ s41598-017-09322-x.

Gröhn, Y. T., D. J. Wilson, R. N. González, J. A. Hertl, H. Schulte, G. Bennett, and Y. H. Schukken. 2004. Effect of pathogen-specific clinical mastitis on milk yield in dairy cows. J. Dairy Sci. 87:33583374. https://doi.org/10.3168/jds.S0022-0302(04)73472-4. 
Hogeveen, H., W. Ouweltjes, C. J. A. M. De Koning, and K. Stelwagen. 2001. Milking interval, milk production and milk flow-rate in an automatic milking system. Livest. Prod. Sci. 72:157-167. https: //doi.org/10.1016/S0301-6226(01)00276-7.

Huybrechts, T., K. Mertens, J. De Baerdemaeker, B. De Ketelaere, and W. Saeys. 2014. Early warnings from automatic milk yield monitoring with online synergistic control. J. Dairy Sci. 97:33713381. https://doi.org/10.3168/jds.2013-6913.

ICAR (International Committee for Animal Recording). 2014. ICAR Recording Guidelines. Int. Agreem. Rec. Pract. 619.

Ouweltjes, W. 1998. The relationship between milk yield and milking interval in dairy cows. Livest. Prod. Sci. 56:193-201. https://doi .org/10.1016/S0301-6226(98)00154-7.

Penry, J. F., P. M. Crump, L. L. Hernandez, and D. J. Reinemann. 2018. Association of milking interval and milk production rate in an automatic milking system. J. Dairy Sci. 101:1616-1625. https:/ /doi.org/10.3168/jds.2016-12196.

Rajala-Schultz, P. J., Y. T. Gröhn, C. E. McCulloch, and C. L. Guard. 1999. Effects of clinical mastitis on milk yield in dairy cows. J.
Dairy Sci. 82:1213-1220. https://doi.org/10.3168/jds.S0022 -0302(99)75344-0.

Supré, K., K. Lommelen, and L. De Meulemeester. 2014. Antimicrobial susceptibility and distribution of inhibition zone diameters of bovine mastitis pathogens in Flanders, Belgium. Vet. Microbiol. 171:374-381. https://doi.org/10.1016/j.vetmic.2014.02.045.

Verbeke, G., and G. Molenberghs. 1997. Linear Mixed Models in Practice: A SAS-Oriented Approach. Springer-Verlag, New York, NY.

Wilson, D. J., R. N. González, J. Hertl, H. F. Schulte, G. J. Bennett, Y. H. Schukken, and Y. T. Gröhn. 2004. Effect of clinical mastitis on the lactation curve: a mixed model estimation using daily milk weights. J. Dairy Sci. 87:2073-2084. https://doi.org/10.3168/jds .S0022-0302(04)70025-9.

Wood, P. 1967. Algebraic model of the lactation curve in cattle. Nature 216:164-165.

Zhao, X., and P. Lacasse. 2008. Mammary tissue damage during bovine mastitis: Causes and control. J. Anim. Sci. 86:57-65. https:// doi.org/10.2527/jas.2007-0302. 